\title{
Pendekatan Perencanaan Desain Wahana Game Esport di Surabaya dengan Menggunakan Konsep Futuristik
}

\author{
Rachman Ardiyanto ${ }^{1}$, Randy Pratama Salisnanda ${ }^{2}$, Sigit Hadi Laksono ${ }^{3}$ \\ 1,2,3 Jurusan Arsitektur, Fakultas Teknik Sipil dan Perencanaan, Institut Teknologi Adhi Tama Surabaya. \\ Email: r.a.ardiyanto@gmail.com
}

\begin{abstract}
Online games are games that require online-based playing devices and if they are competed in a sport, then the sport is called esports. Meanwhile, there is a device that has just emerged to be able to experience real life in the game called Virtual Reality /VR. With VR, it can change the image of a passive game to an active one. Currently, many games are commonly played, competing to make it real by using VR. So it requires a space that creates a special vehicle and place for VR game users. However, in Surabaya, there are no special places to accommodate game fans. In fact, it has the potential to create excellent facilities and make introverted gamers more productive and socially minded. The type of research method used is descriptive method, starting from the case study of LigaGameTV, Jakarta which produces facilities for current and future game fans, as well as knowing the problems that exist for game fans. Then the case study of Spazio Surabaya and Werk12, Germany. Resulting in the concept of "Ergonomic" space, the application of which is about space for circulation. Then the case study Haishang China, Producing the "Expressive and Dynamic" land micro concept, which its application to land must have a distinctive feature. The results of the research are expected to become a forum for game fans, especially as a place to change the view of a passive game to an active one and make a real game.
\end{abstract}

Keywords: Online Games, Virtual Reality, Esport.

\begin{abstract}
Abstrak. Game online merupakan permainan yang membutuhkan perangkat dalam bermain yang berbasiskan online dan jika di kompetisikan dalam cabang olahraga, maka cabang olahraga tersebut bernamakan esport. Sedangkan ada perangkat yang baru muncul untuk bisa masuk merasakan di dalam game secara nyata yang dinamakan Virtual Reality/VR. Dengan adanya VR dapat merubah gambaran game yang pasif menjadi aktif. Saat ini banyak game yang biasa dimainkan, berlomba untuk menjadikan nyata dengan menggunakan VR. Maka membutuhkan ruang yang menciptakan wahana dan tempat khusus pengguna game VR. Namun di Surabaya belum adanya tempat yang khusus mewadahi para penggemar game. Padahal berpotensi untuk menciptakan sarana yang berprestasi dan membuat gamers introvert untuk lebih produktif dan berjiwa sosial. Jenis metode penelitian yang dipakai adalah metode deskriptif, yang dimulai dari studi kasus LigaGameTV, Jakarta. yang menghasilkan fasilitas untuk penggemar game saat ini dan yang akan datang, serta mengetahui permasalahan yang ada pada penggemar game. Kemudian studi kasus Spazio Surabaya dan Werk12, Jerman. Menghasilkan konsep ruang "Ergonomi", yang pengaplikasiannya tentang ruang gerak sirkulasi. Kemudian studi kasus Haishang, China. Menghasilkan konsep mikro lahan "Ekspresif dan Dinamis", yang pengaplikasiannya pada lahan, harus mempunyai sebuah ciri khas. Hasil dari penelitian diharapkan menjadi wadah bagi para penggemar game, khususnya sebagai tempat untuk merubah pandangan game yang pasif menjadi aktif dan menjadikan game secara nyata.
\end{abstract}

Kata Kunci: Game Online, Virtual Reality, Esport.

\section{Pendahuluan}

Dalam perkembangan dunia games online merupakan sebuah kemajuan teknologi yang tidak bisa dianggap remeh, dikarenakan sasaran untuk bermain game, bukanlah hanya remaja, akan tetapi anak-anak, dan dewasa. Dampak dari game pun bermacam-macam. Akan tetapi lebih banyak ke hal negatif, seperti: membuang waktu, malas bergerak, dan menjadikan introvert.

Berbagai cara dilakukan untuk mengatasi dampak negatif ini, namun cara yang paling efektif adalah mengikuti komunitas-komunitas games. Dengan mengikuti komunitas games, dapat 
mengarahkan hal negatif tersebut menjadi lebih positif, seperti dibimbing untuk mengasah game, mengatur waktu, dll. Namun wadah dan tempat bagi komunitas di Surabaya ini, masih belum ada. Kebanyakan mereka hanya bersosialisasi melalui dunia maya, baik sosmed ataupun di dalam game. Adapun yang bertemu secara offline di tempat seperti café, itupun berpindah-pindah, membuat orangorang malas untuk bergabung. Selain berkumpul, sarana dan prasarana permanen untuk diciptakannya sebuah tournament game belum ada di Surabaya.

Dengan adanya tempat Wahana Games Esport ini, merupakan jawaban yang tepat terhadap permasalahan yang terjadi untuk saat ini. Dikarenakan dapat mewadahi dan juga sebagai tempat sarana dan prasarana berkumpulnya para komunitas games, sehingga vendor game bisa berkantor di dalam kawasan, dan berhubungan secara langsung kepada pemainnya.

Selain sarana dan prasarana, di perancangan Wahana Games Esport ini juga mengubah gaya bermain games yang pada dasarnya bersifat pasif menjadi aktif, dengan diadakannya sebuah wahana games yang menggunakan konsol VR/Virtual Reality, dengan konsep game berlevel dan genre yang berbeda dari setiap levelnya.

\section{Tinjauan Pustaka}

Game online adalah permainan video yang dimainkan selama beberapa bentuk jaringan komputer, menggunakan komputer pribadi atau konsol video game. Game online adalah teknologi daripada genre, sebuah mekanisme untuk menghubungkan pemain bersama daripada pola tertentu gameplay (Surbakti, 2017). Dengan berbagai Macam Games seperti : Game PC/Komputer, Game Konsol (PSP, PlayStation, NitendoWii, dll), Game Simulasi (VR dan Reality Game), Mobile Game/Game HP. Dalam permainan game, terdapat banyak sekali Jenis dalam games, yaitu : FPS/First Person Shooter, TPS/Thirt Person Shooter, RTS/Game Strategi, MOBA, Game RPG, MMO/Massively Multiplayer Online, MMORPG, Action Game/Game Aksi, Fighthing Game/Game Petarungan, Adventure Game, Simulasi, Sport Game, Racing Game.

eSports atau electronik sport adalah bidang olahraga yang menggunakan game sebagai bidang kompetitif utama. Wahyunanda Kusuma Pertiwi (2017) mengutarakan bahwa Olahraga elektronik (juga dikenal sebagai permainan kompetitif, permainan pro, ESports, E-Sports, electronic sports, atau pro-gaming di Korea Selatan) merupakan suatu istilah untuk kompetisi Permainan video pemain jamak, umumnya antara para pemain professional. Lebih lanjut juga menegaskan bahwa ESport merupakan olahraga digital yang terorganisir dengan pelatihan khusus seperti halnya atlet profesional sepak bola, bulutangkis, ataupun basket (Kurniawan, 2019).

Futuristik adalah sebuah gerakan seni murni Italia dan sebuah pergerakan kebudayaan pertama dalam abad ke-20 yang diperkenalkan secara langsung kepada masyarakat luas. Bermula dari konsep dalam pergerakan sastra, kemudian merasuk ke dalam bidang kesenian seperti: seni lukis, seni patung, seni musik, desain dan arsitektur. Falsafah yang dipakai oleh kaum futurism hampir sebagian besar diambil dari latar belakang sejarah kemunculan Moderism. Sebab Futurism ini merupakan gerakan awal lahirnya Moderism. Mempunyai konsep masa depan terutama sesuai dengan paradigma perkembangan arsitektur. Bentuk yang didapat bukan bentuk-bentuk tertentu saja, tetapi bentuk bebas yang dekonstruksi, Memanfaatkan kemajuan di era teknologi melalui struktur dan konstruksi menggunakan struktur yang dekonstruksi, Memakai bahan-bahan pre-fabrikasi dan bahan-bahan baru, seperti kaca, baja, aluminium, dll, Memunculkan bentuk-bentuk baru dari arsitektur yang analogi dengan musimnya (Dosen et al., 2019).

Sedangkan menurut krisdianto, Arsitektur Futuristik atau futurisme dimulai pada awal abad ke-20 dengan bentuk bangunan yang ditandai oleh anti-historicism dan garis panjang mendatar, kecepatan, emosi dan urgensi yang artistik dan gaya ini dimulai pada Italia dan berlangsung pada tahun 1909 sampai 1944.Dalam ilmu arsitektur, arsitektur futuristik masih belum dapat digolongkan ke dalam kriteria arsitektur modern, late modern maupun post modern. Ciri-ciri Arsitektur Futuristik adalah:

- Satu gaya Internasional atau tanpa gaya (seragam), Merupakan suatu arsitektur yang dapat menembus budaya dan geografis.

- Berupa khayalan, idealis 
- Bentuk tertentu, fungsional Bentuk mengikuti fungsi, sehingga bentuk menjadi monoton karena tidak diolah.

- Ornamen adalah suatu kejahatan sehingga perlu ditolak, Penambahan ornamen dianggap suatu hal yang tidak efisien.

- Semakin sederhana merupakan suatu nilai tambah terhadap arsitektur tersebut.

- Singular (tunggal)

- Nihilism, penekanan perancangan pada space.

- Ekspos material bangunan.

Dengan melihat pengerian futuristik yang ada, maka diambil kesimpulan pedoman dalm perencanaan berdasarkan ungkapan futuristik, yaitu:

- Mempunyai konsep masa depan terutama sesuai dengan paradigma perkembangan arsitektur.

- Bentuk yang didapat bukan bentuk-bentuk tertentu saja, tetapi bentuk bebas yang dekonstruksi.

- Memanfaatkan kemajuan di era teknologi melalui struktur dan konstruksi menggunakan strutur yang dekonstruksi. (Krisdianto et al., 2018)

\section{Metode Penelitian}

Metode penelitian yang digunakan adalah penelitian deskriptif, penelitian deskritif yaitu penelitian yang bertujuan menyajikan gambaran fenomena, gejala, umumnya dilakukan dengan metode survei, pengamatan, studi kasus, studi korelasi, dll. Adapun beberapa cara dalam mengumpulkan data yang akan dipakai untuk penelitian ini di antaranya yaitu: analisa data dengan metode observasi (pengamatan dan pencatatan secara sistematis baik positif/negatif), dan documenter (mempelajari history, maupun permasalahannya).

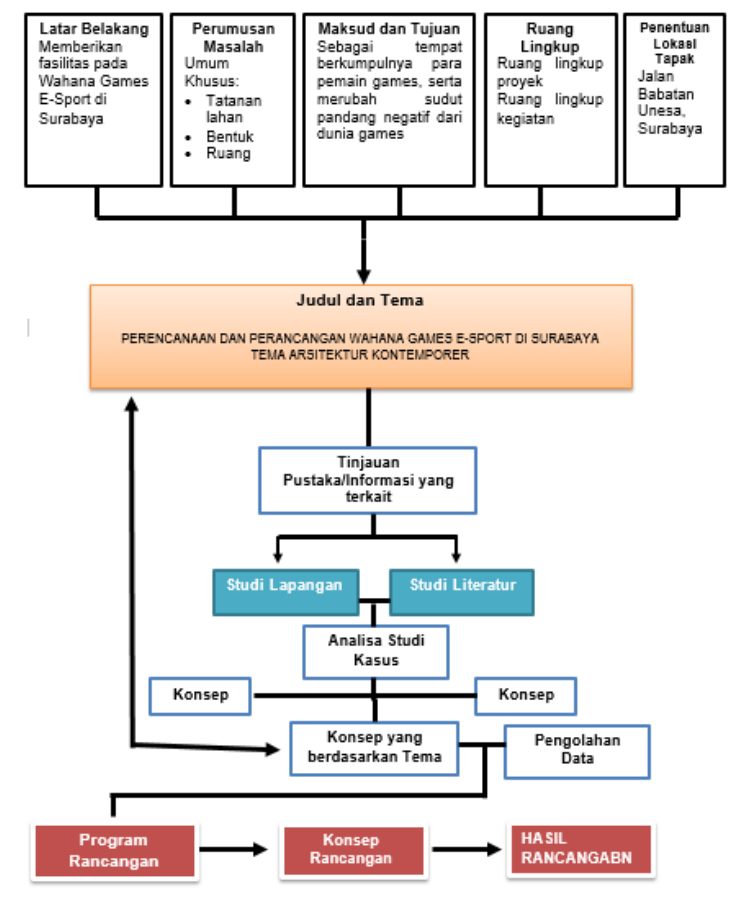

Gambar 1. Gambar Metode Penelitian

Setelah mendapatkan data yang telah di dapatkan dari hasil survei lapangan dan sumber yang dapat dijadikan data, penelitian selanjutnya adalah pengumpulan data yang dapat digunakan antara lain : 'Library Research" Pengumpulan data yang didapat dengan membaca buku karya dari para ahli atau sebelumnya yang melakukan penelitian dan maupun dari bacaan-bacaan lainnya yang berhubungan, "Field Research" merupakan penelitian secara langsung yang berada di lapangan yang berkaitan dengan jenis penelitian yang di pakai. 
Dari alur pemikiran tersebut, menciptakan latar belakang yang dijadikannya sebuah karya ilmiah, kemudian merumuskan masalah, kemudian memberikan maksud dan tujuan dari terciptanya Wahana Games Esport di Surabaya, kemudian melihat keadaan ruang lingkup sebagai tempat terbangunnya Wahana Games Esport di Surabaya, kemudian menentukan lokasi terbangunnya projek tersebut. Setelah semua telah tertata, kemudian dikerucutkan untuk mengambil judul karya ilmiah dan tema yang cocok untuk terciptanya rancangan "Wahana Games Esport". Setelah terkumpul, kemudian melakukan studi banding dari lapangan dan literatur, dalam terciptanya karya ilmiah tersebut, kemudian diolah dan menghasilkan sebuah konsep, yang kemudian melakukan rancangan dari data-data tersebut.

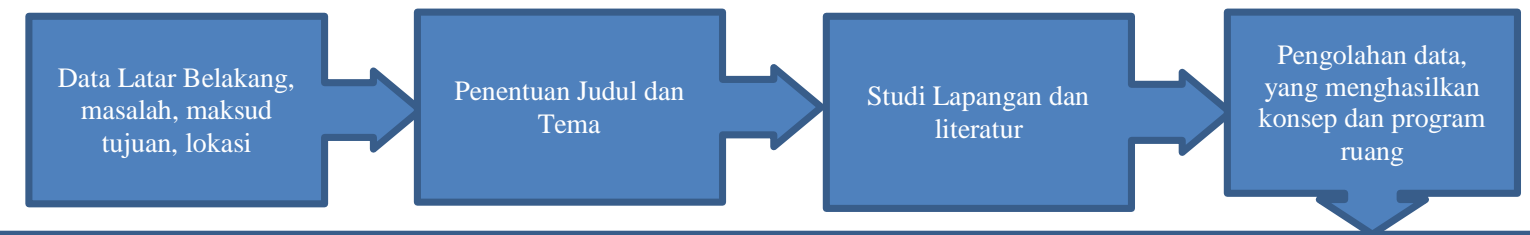

Mendapatkan hasil rancangan

Gambar 2. Gambar Metode Perancangan

\section{Studi Preseden}

Studi Preseden terbagi menjadi dua, yaitu studi kasus lapangan dan studi kasus literatur. Studi kasus lapangan menghasilkan studi nyata tentang apa saja yang terjadi, Sebagai usaha mencari referensi yang relevan dengan kasus yang di susun pada karya ilmiah. Berikut apa saja yang didapatkan untuk mengaplikasiannya terhadap karya ilmiah.

Studi Kasus Lapangan:

LigaGameTV, Jakarta

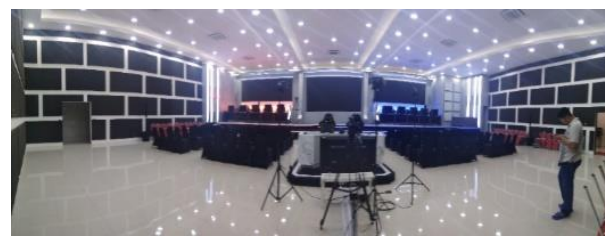

Spazio, Surabaya

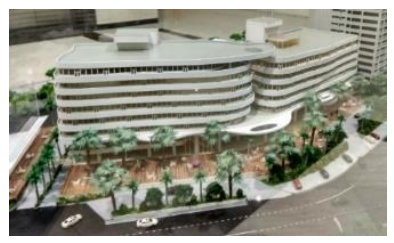

Gambar 3. Gambar Studi Lapangan

Sumber: Data Pribadi

Untuk LigaGame TV, dipilih berdasarkan alasan: LigaGameTV dipilih karena menjadi tempat yang telah mengelolah semua tentang dunia game seperti: streaming, mewadahi komunitas, menciptakan time sport, penyelenggara tournamen game, dan pemberian info terbaru terhadap dunia game. Sehingga menjadi studi yang mendapatkan permasalahan, fasilitas, sarana dan prasarana, serta hal-hal yang berhubungan dengan game. Sedangkan untuk Spazio, Surabaya ini dipilih dikarenakan Bangunan memiliki sistem sirkulasi yang jelas dan terarah, Lebih mengutamakan public space seperti teras yang luas yang berfungsi sebagai tempat bersosialisasi, Sirkulasi parkir dan loading dock berada pada belakang bangunan, Lebih ramah lingkungan yang dikarenakan banyak ruang yang bersifat terbuka, dan memanfaakan penghawaan alami.

Studi Kasus Literatur:

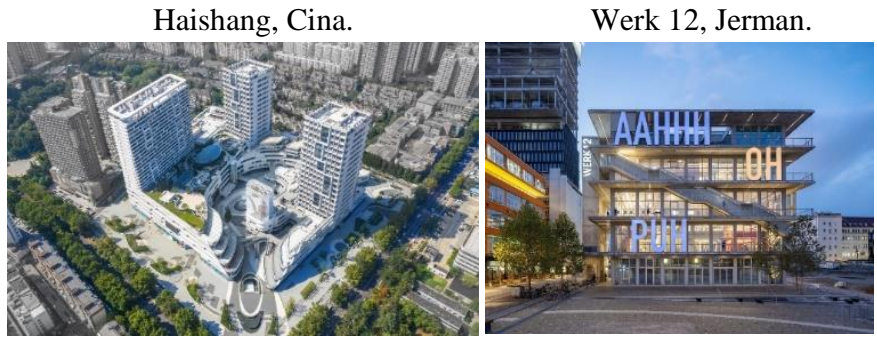

Gambar 4. Gambar Studi Lapangan

Sumber: Archdaily.com 
Studi literatur yang diambil untuk membuat desain Wahana Game Online di Surabaya, terdapat 2 studi kasus literatur, yaitu : Haishang, China dan Werk12, Jerman. Untuk Haishang, China dipilih karena penataan pola sirkulasi lahan yang mempunyai ciri khas dan jelas, bangunan terpisah namun dapat menampilkan satu kesatuan, dengan terhubungnya bangunan di lantai bawah dan atasnya menyambung, sehingga bangunan terasa menyatu, terlihat berbeda antar bangunan dari tower dan ada ruang untuk orang berjalan yang cukup luas antar bangunan, serta bangunan mempunyai tekstur dan warna yang sama, sehingga kesan satu kesatuan, lebih terasa. Lahan Haishang, China sangat meminimalisir untuk sirkulasi kendaraan, sehingga lahan mempunyai banyak ruang sirkulasi untuk pengguna. Untuk studi kasus Werk12, diambil karena Bangunan merupakan rancangan yang berhubungan dengan olah gerak, Bangunan mencakup beberapa aktivitas baik kantor, dan entertainment.

\section{Pembahasan Rancangan}

Wahana games esport ini berfungsi sebagai wahana games yang bersifat aktif, dikarenakan terdapat wahana permainan seperti RPG, MMORPG, dll. Yang dituangkan secara nyata dengan menggunakan Virtual Reality. Dengan adanya wahana tersebut maka membutuhkan banyak ruang untuk melakukan kegiatan. Rancangan yang diterapkan dari segi fungsi dari wahana permainan, yang tersebar ke setiap bangunan. Dapat dilihat pada sistem organisasi makro sebagai berikut:

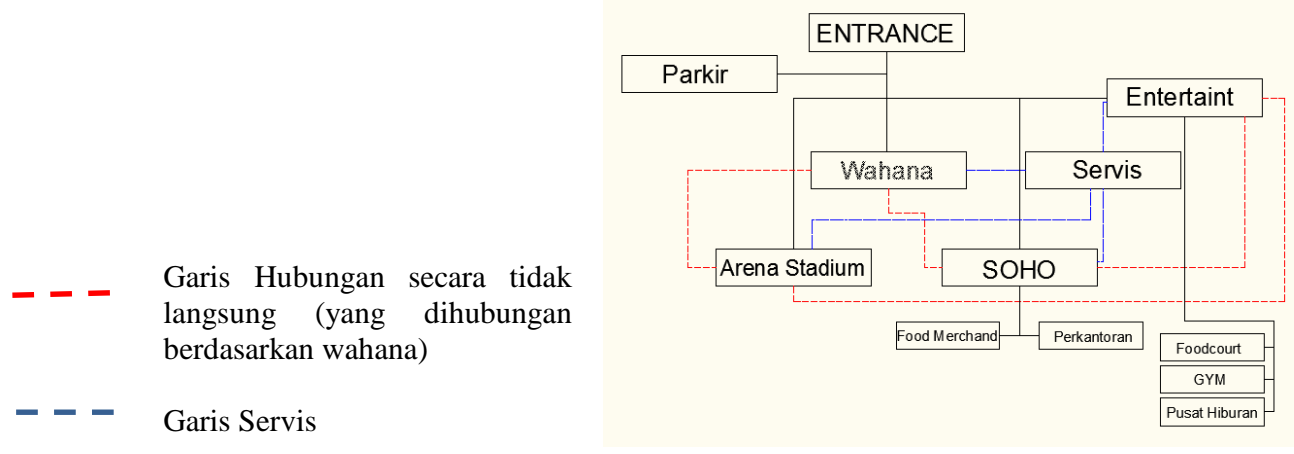

Gambar 5. Organisasi Ruang Makro

Terlihat dengan jelas dari skema organisasi ruang makro, bahwasannya semua bangunan terhubung oleh wahana permainan, yang berada pada setiap gedung. Selain dari fungsi ruang yang menjadi satu kesatuan, bentuk dan tatanan Lahan memiliki satu kesatuan yang saling terhubung.

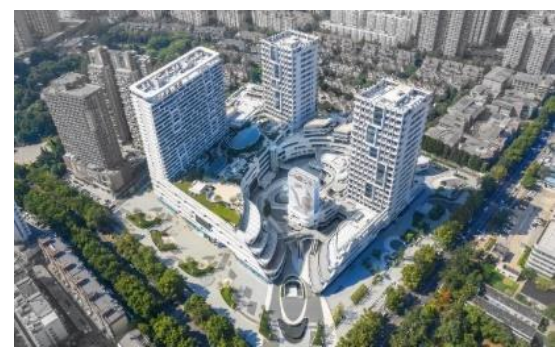

Gambar 6. Referensi bentuk dan tatanan lahan

Setelah memahami seperti apa fungsi bangunan, bentuk dan tatanan lahan. kemudian mengambil kesimpulan dari studi lapangan dan studi literature, untuk menciptakan tema, dan konsep. Terdapat kelebihan dan kekurangan dari studi banding tersebut dalam terbentuknya Wahana Game Esport di Surabaya, agar menghasilkan sebuah rancangan dengan fasilitas yang sesuai.

\subsection{Konsep dan Tranformasi}




\section{Tema Perancangan}

Pemilihan tema yang dipilih adalah tema "arsitektur kontemporer" yang mempunyai alasan, bahwasannya arsitektur kontemporer, mempunyai desain yang lebih maju, variatif, fleksibel dan inovatif, baik secara bentuk maupun tampilan, jenis material, pengolahan material, maupun teknologi yang dipakai dan menampilkan gaya yang lebih baru.

Dengan pemilihan tema arsitetuk kontemporer. Mempunyai tujuan agar kebutuhan para gamer dalam hal kenyamanan, dan keamanan. Kemudian setelah tema terbentuk, kemudian menciptakan Konsep Makro

\section{Konsep Makro}

Makro konsep pada rancangan wahana game esport di Surabaya, mengamil konsep Arsitektur "Futuristik". Yang bertujuan memberikan kesan dari bentukan masa depan, dengan menampilkan tampilan yang seakan-akan sepeti berada di masa depan dengan pemberian vegetasi pada beberapa tempat, agar terlihat masa depan juga memperlihatkan keselarasan antara alam dan teknologi. Gambar 7 menunjukkan adanya sirkulasi yang luas, serta bangunan yang tidak terikat, cukup menerangkan bahwasannya Wahana Games Esport ini sudah menerapkan konsep "futuristik".

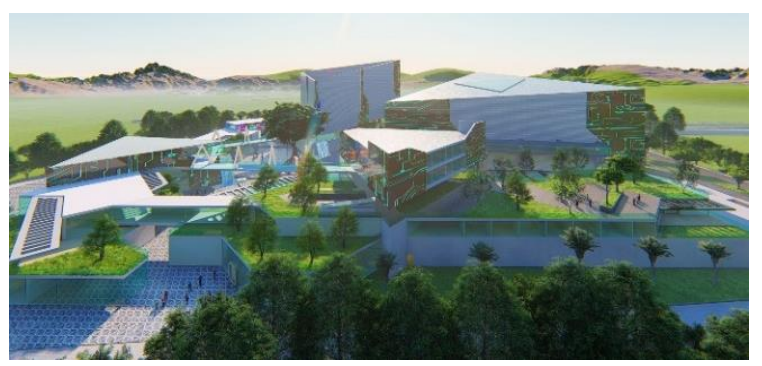

Gambar 7. Perspektif belakang

\section{Konsep Mikro Bentuk "Futuritik"}

Bentuk bangunan yang menggunakan konsep futuristik berawalkan dari bentuk bangunan yang lebih mencerminkan masa depan yang tidak terikat dengan prinsip/aturan yang ditetapkan, melainkan bisa berkarya secara bebas, namun menghindari dari bentukan dan tampilan seperti bangunan tradisional.

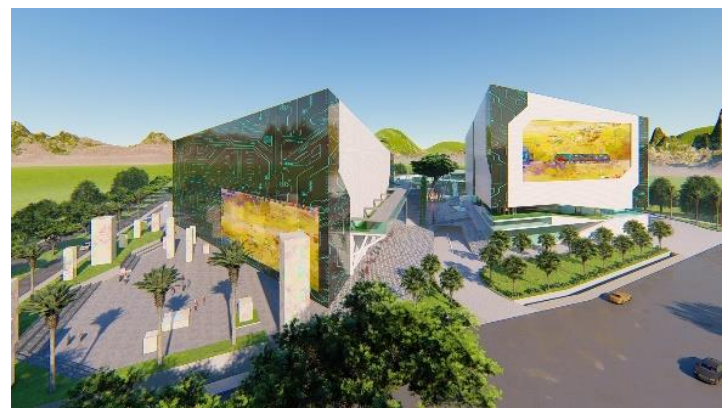

Gambar 8. Perspektif depan

Sumber: Data Pribadi

Bentuk bangunan yang berbentuk segitiga dengan ornament permainan LED pada dinding yang di finishing berwarna hitam, menguatkan kesan dari konsep "Futuristik".

\section{Konsep Mikro Lahan "Ekspresif dan Dinamis}

Konsep mikro pada lahan adalah ekspresif dan dinamis, yang bertujuan untuk memperlihatkan tatanan lahan yang tidak monoton, yang mengambil studi literature Haishang, china. Lahan pada haishang di china ini, mempunyai tatanan lahan yang ekspresif, dengan memaksimalkan sirkulasi pengguna jalan, meminimalisir sirkulasi mobil, dan bangunan saling menyambung pada area lantai 2 , dsb. 


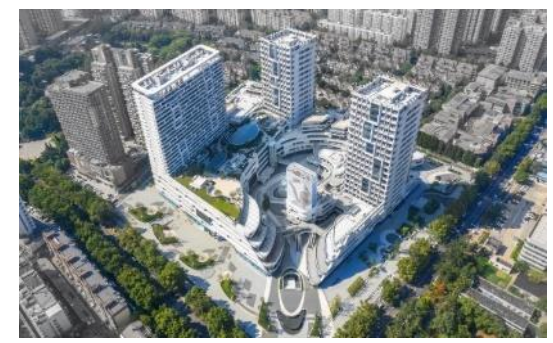

Gambar 9. Gambar Studi Lapangan Sumber: Archdaily.com

Tatanan yang ekspresif, dari peletakkan bangunan segitiga yang disusun secara melingkar, dan menjadikan lahan mempunyai orientasi kedalam. Bentukan dinamis tercipta dari permainan besar kecilnya bangunan dan perbedaan ketinggian dari setiap bangunan, serta bangunannya menyambung dengan keadaan yang tidak monoton, melainkan dengan bentukan yang berbeda satu sama lain.

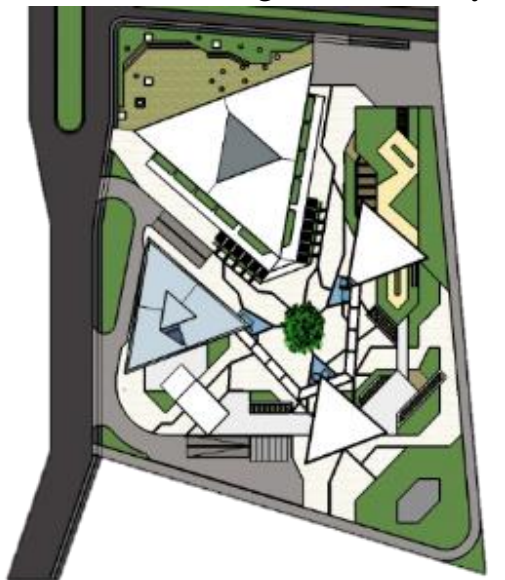

\section{Gambar 10. Gambar Studi Lapangan}

Sumber: data pribadi

\section{Konsep Mikro Ruang "Ergonomi”}

Konsep mikro ergonomi diambil agar penyesuaian ruang, agar memberikan kenyamanan bagi pengguna, seperti pemberian perabotan yang tidak berlebihan/secukupnya, serta membuat sirkulasi lebih nyaman dan tidak memberikan ruang secara berlebihan, supaya tetap menciptakan ruang yang nyaman dan aman.

\section{Transformasi dan Desain}

Setelah tersusun konsep dan kebutuhan bangunan, diperlukan perubahan dan desain dari bentuk, ruang, dan lahan, dengan melalui tahap-tahap sebagai berikut:

\section{a. Desain Bentuk}

Mengambil contoh bangunan dari bentukan stadium yang berbentuk segitiga. Bentukan stadium yang berbentuk segitiga mempunyai alasan seperti: bentukan segitiga bisa sebagai pembelok dan pemecah angin, bentukan segitiga merupakan bentukan yang menekankan dan menciptakan/menunjuk entry point sebagai bagian yang menarik dan menciptakan sebuah ikon.
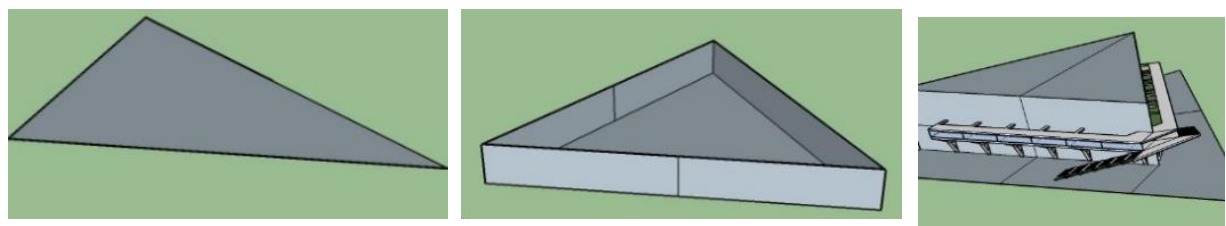

Gambar 10. Transformasi Bentuk 
Mengambil contoh bangunan dari bentukan stadium yang berbentuk segitiga. Bentukan stadium yang berbentuk segitiga mempunyai alasan seperti: bentukan segitiga bisa sebagai pembelok dan pemecah angin, bentukan segitiga merupakan bentukan yang menekankan dan menciptakan/menunjuk entry point sebagai bagian yang menarik dan menciptakan sebuah ikon.

Transformasi bentuk dari gedung stadium, berawal dari bentuk segitiga sama sisi, kemudian di tinggikan, dan diberi sirkulasi pada bagian luarnya, yang berfungsi sebagai tempat masuknya ke area stadium.

Bangunan pada lahan Wahana Games Esport berawal dari bangunan stadium yang berbentukkan segitiga, kemudian diikuti oleh bangunan sekitarnya yang berbentuk segitiga juga.

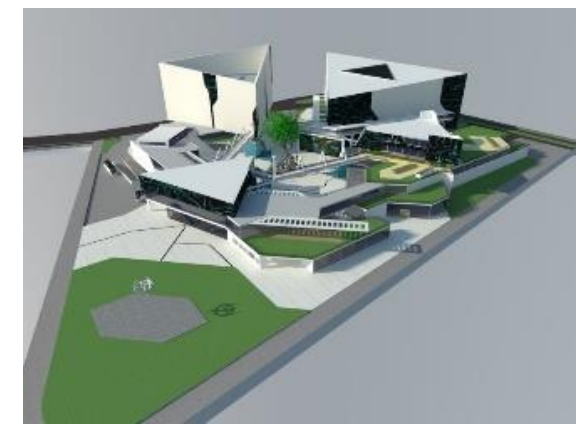

\section{Gambar 11. Desain Bentuk Bangunan Keseluruhan}

4 bangunan berbentukkan segitiga, yang disatukan menjadi satu kesatuan dengan cara menyambungkan bangunan pada lantai 2/lantai berikutnya dengan bentukkan yang tidak kaku, melainkan dengan bentuk yang futuristik, sehingga bentuk bangunan menjadi satu kesatuan, namun tetap mempertahankan konsep futuristik.

\section{b. Desain Ruang}

Pada desain ruang terdapat program ruang, sedangkan program ruang adalah tahap penyusunan kebutuhan ruang yang merupakan hasil dari studi banding, sehingga bisa dijadikan patokan/refrensi untuk diaplikasikan ke rancangan, seperti penyusunan ruang, jenis ruang, besaran, dan organisasi ruang.

Tabel 1. Kebutuhan Ruang

\begin{tabular}{|l|l|l|}
\hline Bangunan & Zonifikasi & Luas lantai dasar \\
\hline Entertain & Publik & 3300 \\
\hline Wahana & Semi Publik & 2800 \\
\hline Stadium & Publik & 7122,8 \\
\hline Soho & Private & 3600 \\
\hline Total & & $16822 \mathrm{~m}^{2}$ \\
\hline Luas Lahan & $3 \mathrm{Ha}$ \\
\hline Lahan Terbangun & $60 \%$ \\
\hline
\end{tabular}

Pada rancangan wahana game esport di Surabaya ini, memiliki 4 bangunan utama, yaitu bangunan Stadium (sebagai fasilitas untuk mengadakan tournamen dan acara yang mengumpulkan banyak massa), bangunan Wahana (bangunan dengan fungsi sebagai tempat berbagai genre dan jenis game, yang dijadikan secara nyata), bangunan Entertain (fungsi bangunan sebagai tempat area makan, area berbelanja, dll), dan bangunan Soho (sebagai tempat perkantoran sewa/tetap, yang biasanya vendor menginginkan kantor khusus).

Sedangkan untuk konsep ruang yang di aplikasikan secara keseluruhan adalah ergonomi yang mempunyai ciri seperti: sirkulasi yang nyaman, tidak banyak ruangan, dan harmonisasi. Mengambil contoh bagian "check point" yang mengambil sirkulasi yang lebar agar menciptakan kenyamanan, serta memanfaatkan keadaan sekitar yang kaya angin sehingga ruangan bersifat terbuka, dan masuknya cahaya matahari kedalam ruangan 

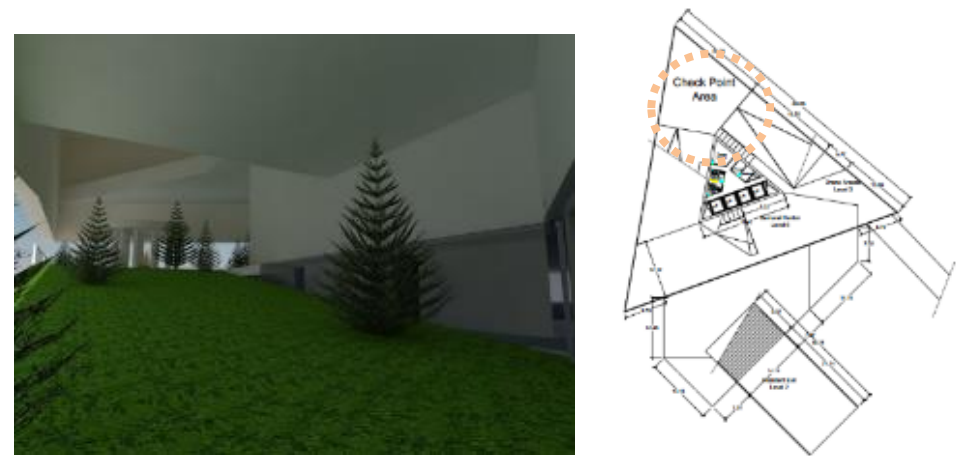

Gambar 12. Bentuk Ruang Check Point

\section{c. Desain Tatanan Lahan}

Tatanan lahan terdiri dari 4 bangunan yang berbentuk segitiga, kemudian disusun berdasarkan pola yang menghadap kedalam, sehingga bangunan menghadap kedalam. Kemudian disambung oleh podium yang saling terhubung, sehingga bangunan terlihat menjadi satu kesatuan, kemudian terdapat pengurangan yang disesuaikan dengan kebutuhan ruang, selanjutnya pemanfaatan jalur hijau yang disebar pada lahan, dan ruang diatas bangunan.
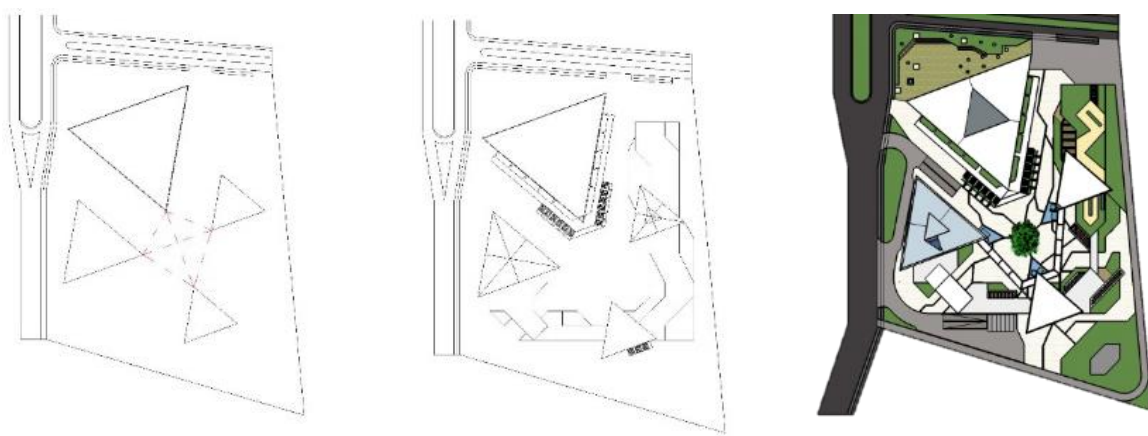

Gambar 13. Transformasi Lahan

Setelah semua bangunan ditata pada lahan yang menghadap kedalam, akan menciptakan sebuah ikon berupa monumen pada tengah lahan, yang menjadikan bangun menjadi lebih ekspresif, dan juga perngaturan pola sirkulasi pengunjung dan kendaraan. Kemudian dinamis terdapat pada perubahan besar kecilnya bangunan, serta tinggi rendahnya bangunan pada lahan. Kemudian lahan yang tidak ada bangunan, difungsikan sebagai tempat untuk tempat bermain game bagi para komunitas.
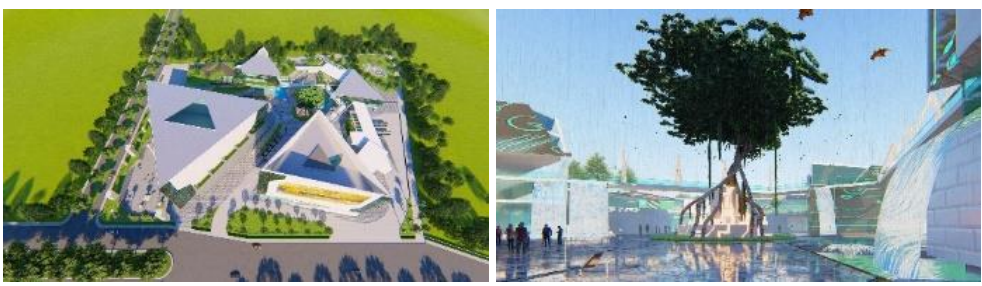

Gambar 14. Bentukan 3D lahan dan ikon monument tengah lahan

Pada setiap sudut lahan difungsikan sebagai tempat berkumpul para penggemar game, dan komunitas, dan mempunyai ciri khas dari dalam game, seperti skluptur, dan taman rerumputan yang di kelilingi pohon. 


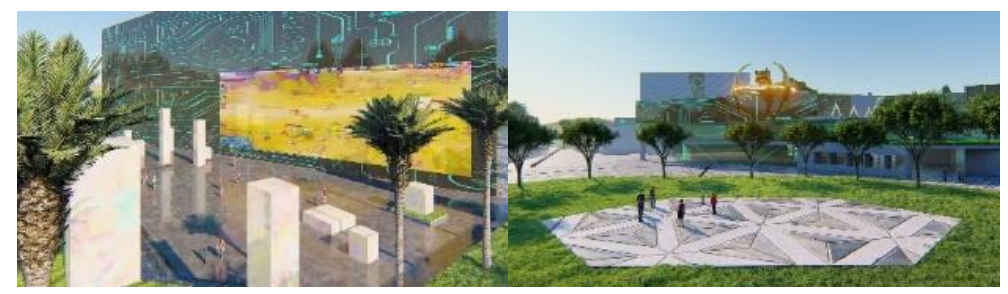

Gambar 15. Sudut lahan yang dimaksimalkan

Bangunan dari depan terlihat besar dan tinggi, mempunyai tujuan agar pengunjung dibuwat penasaran pada dalam lokasi tersebut serta menghasilkan konsep ekspresif juga. Dengan orientasi bangunan menghadap kedalam, konsep dinamis pada lahan menjadi semakin kuat dengan terciptanya view yang berbeda saat di dalam lokasi wahana game esport di Surabaya.

\section{d. Desain Struktur}

Desain struktur pada Wahana Games Esport menggunakan struktur Baja. Mengambil contoh seperti bangunan Wahana, yang menggunakan struktur baja, dengan core yang bersistemkan kantilever yang diperkuat oleh suspender baja secara vertical, yang menerus dengan sistem.

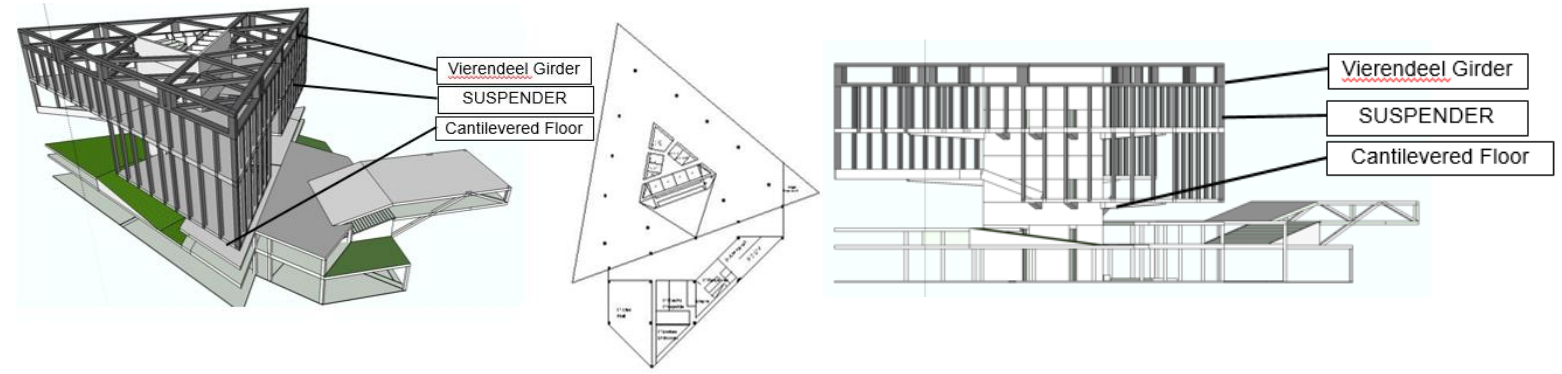

Gambar 16. Detail Struktur

Vierendel Girder dipasang pada bagian atas bangunan dengan bentuk segitiga, bertujuan sebagai penopang beban pada lantai bangunan, agar lebih kokoh.

\section{Kesimpulan}

Hasil dari Pendekatan Perencanaan Desain Wahana Game Esport di Surabaya menghasilkan sebuah tempat yang yang bisa mewadai para gamer di Surabaya, dengan tujuan bisa menjadikan lebih aktif, bersosialisasi, dan berkompetisi. Menjadikan aktif dengan menggunakan perangkat game bernamakan VR. Dengan pemilihan tempat di Surabaya yang melalui proses seperti ruang lingkup dan latar belakang, mempunyai maksud mengatasi masalah yang ada.

Desain dari wahana game esport mengusung tema kontemporer, tema kontemporer tidak mempunyai batasan, sehingga cocok untuk bangunan yang bernuansakan game. Selain tema, konsep makro pada Wahana Games Esport berkonsepkan futuristik yang menciptakan gambaran tentang sebuah teknologi bangunan di masa depan, dengan Mikro konsep bentuk yang sama yaitu "Futuristik" seperti dijelaskan diatas, arsitektur futuristik menggambarkan masa depan pada bangunan, seperti pemberian $L E D$ pada bangunan. Mikro Konsep ruang "Ergonomi" menciptakan sebuah ruang yang nyaman, serta sirkulasi yang bebas. Sedangkan untuk Mikro konsep tatanan lahan "Ekspresif dan Dinamis", dimana ekspresif didapat dengan penempatan bangunan berbentuk segitiga, kemudian di susun dengan pola yang menghadap ke dalam, dan pengaturan pola sirkulasi bagi pengunjung dan kendaraan. Sedangkan dinamis di dapatkan dari tinggi rendahnya bangunan, dan ukuran bangunan, yang menciptakan kondisi yang saling terus menerus/perubahan yang mendasar pada lahan. Struktur yang dipakai adalah struktur baja, yang diaplikasikan pada semua rancangan bangunan. 


\section{Referensi}

Dosen, S. et al. (2019) 'SHOPPING MALL DI AMURANG. Arsitektur Futuristik', Jurnal Arsitektur DASENG, 8(2), pp. 830-839.

Krisdianto, A. et al. (2018) 'Penerapan Arsitektur Futuristik Terhadap Bangunan GUNDAM BASE INDONESIA DI JAKARTA', Arsitektur PURWARUPA, 02, pp. 9-16.

Kurniawan, F. (2019) 'E-Sport dalam Fenomena Olahraga Kekinian E-Sport in the Current Sports Phenomenon', JORPRES (Jurnal Olahraga Prestasi), 15(2), pp. 61-66.

Surbakti, K. (2017) 'Pengaruh Game Online Terhadap Remaja', Jurnal Curere, 01(01), pp. 28-38. 


\section{Halaman ini sengaja dikosongkan}

